\title{
Diagnostic doses and times for Phlebotomus papatasi and Lutzomyia longipalpis sand flies (Diptera: Psychodidae: Phlebotominae) using the CDC bottle bioassay to assess insecticide resistance
}

David S. Denlinger, Joseph A. Creswell, J. Laine Anderson, Conor K. Reese and Scott A. Bernhardt*

\begin{abstract}
Background: Insecticide resistance to synthetic chemical insecticides is a worldwide concern in phlebotomine sand flies (Diptera: Psychodidae), the vectors of Leishmania spp. parasites. The CDC bottle bioassay assesses resistance by testing populations against verified diagnostic doses and diagnostic times for an insecticide, but the assay has been used limitedly with sand flies. The objective of this study was to determine diagnostic doses and diagnostic times for laboratory Lutzomyia longipalpis (Lutz \& Nieva) and Phlebotomus papatasi (Scopoli) to ten insecticides, including pyrethroids, organophosphates, carbamates, and DDT, that are used worldwide to control vectors.

Methods: Bioassays were conducted in 1,000-ml glass bottles each containing 10-25 sand flies from laboratory colonies of L. longipalpis or P. papatasi. Four pyrethroids, three organophosphates, two carbamates and one organochlorine, were evaluated. A series of concentrations were tested for each insecticide, and four replicates were conducted for each concentration. Diagnostic doses were determined only during the exposure bioassay for the organophosphates and carbamates. For the pyrethroids and DDT, diagnostic doses were determined for both the exposure bioassay and after a 24-hour recovery period.

Results: Both species are highly susceptible to the carbamates as their diagnostic doses are under $7.0 \mu \mathrm{g} / \mathrm{ml}$. Both species are also highly susceptible to DDT during the exposure assay as their diagnostic doses are $7.5 \mu \mathrm{g} / \mathrm{ml}$, yet their diagnostic doses for the $24-\mathrm{h}$ recovery period are $650.0 \mathrm{\mu g} / \mathrm{ml}$ for Lu. longipalpis and $470.0 \mathrm{\mu g} / \mathrm{ml}$ for P. papatasi.

Conclusions: Diagnostic doses and diagnostic times can now be incorporated into vector management programs that use the CDC bottle bioassay to assess insecticide resistance in field populations of Lu. longipalpis and P. papatasi. These findings provide initial starting points for determining diagnostic doses and diagnostic times for other sand fly vector species and wild populations using the CDC bottle bioassay.
\end{abstract}

Keywords: Lutzomyia longipalpis, Phlebotomus papatasi, Insecticide resistance, CDC, WHO, Bottle bioassay, Pyrethroid, Organophosphate, Carbamate, DDT

\footnotetext{
* Correspondence: scott.bernhardt@usu.edu

Department of Biology, Utah State University, Logan, Utah, USA
} 


\section{Background}

Insecticide resistance continues to be a threat to the success of insect vector control programs that incorporate synthetic chemical insecticides [1]. Insecticide resistance is a heritable phenotype that allows arthropods to survive an exposure to an insecticide that would normally kill a susceptible population [2-4]. Today, insecticide resistance to all classes of synthetic insecticides has been found in the major insect vectors $[1,5]$. Managing insecticide resistance requires timely, accurate data through resistance monitoring and insecticide evaluation to assess a vector species' susceptibility to insecticides. These aspects can be used to develop effective strategies at managing vector populations [6]. The primary way to assess insecticide resistance is to use insecticide susceptibility bioassays.

The Centers for Disease Control and Prevention (CDC) bottle bioassay is one technique used to measure a vector species' susceptibility to insecticides [7, 8]. This bioassay is an economical and portable alternative to the World Health Organization's (WHO) exposure kit bioassay, especially in geographic regions where the WHO bioassay cannot be implemented [9-11]. Another benefit of the CDC bottle bioassay is that the materials, including the glass bottles, can be locally acquired and prepared on site [12].

Sand flies (Diptera: Psychodidae: Phlebotominae) require resistance monitoring because they have been, and continue to be, actively targeted with insecticides [13-16]. Fewer than seventy species of sand flies, including Lutzomyia longipalpis (Lutz \& Nieva) and Phlebotomus papatasi Scopoli, are capable of vectoring Leishmania spp. parasites, infection with which causes leishmaniasis, a world-wide disease currently infecting millions of people $[17,18]$. Sand fly populations around the world have been exposed to the four main classes of insecticides: organochlorines, organophosphates, carbamates and pyrethroids. Insecticide exposure has been both intentional in directed vector control efforts and inadvertent as part of vector control efforts targeted against other insects [6, 13, 17, 19-24]. Populations of sand flies have been found to be tolerant or resistant, using the WHO exposure kit bioassay and diagnostic doses derived for mosquitoes, to the insecticides used worldwide $[6,19-30]$. Despite these examples, there is a gap in understanding the prevalence of insecticide resistance in sand fly populations. This has been attributed to challenges in collecting the necessary number of live flies for the bioassays and because there is a lack of a standardized sand fly bioassay [31].

To test an insect vector species' susceptibility status to an insecticide using the CDC bottle bioassay, a diagnostic dose and diagnostic time are needed for that insecticide [8]. A diagnostic dose is the lowest dose of an insecticide that causes $100 \%$ mortality in a susceptible population between 30 and 60 minutes, the diagnostic time [8]. There have been few published studies that have determined diagnostic doses for phlebotomine sand flies using the CDC bottle bioassay. In Colombia, Santamaría et al. [32] determined the diagnostic dose of lamb$\mathrm{da}(\lambda)$-cyhalothrin to be $10.0 \mu \mathrm{g} / \mathrm{ml}$ for $\mathrm{Lu}$. longipalpis. One concern with this finding is that Santamaría et al. [32] only tested three concentrations of lambda $(\lambda)$-cyhalothrin $(10.0,50.0$, and $100.0 \mu \mathrm{g} / \mathrm{ml})$, which makes it difficult to identify a precise diagnostic dose and diagnostic time because of the large differences between the doses tested [33]. Also working with Lu. longipalpis, Marceló et al. [33] determined the diagnostic doses and diagnostic times for malathion, deltamethrin, and $\operatorname{lambda}(\lambda)$ cyhalothrin to be $75.0 \mu \mathrm{g} / \mathrm{ml}$ in 25 minutes, $10.0 \mu \mathrm{g} / \mathrm{ml}$ in 35 minutes and $15.0 \mu \mathrm{g} / \mathrm{ml}$ in 30 minutes, respectively. Diagnostic doses and diagnostic times for fieldcollected Lu. evansi, an important vector of Le. infantum in the Americas, have been previously described as $7.0 \mu \mathrm{g} / \mathrm{ml}$ in 10 minutes for deltamethrin and $3.5 \mu \mathrm{g} / \mathrm{ml}$ in 10 minutes for lambda $(\lambda)$-cyhalothrin [20].

Dose-response survival curves to determine lethal concentrations causing $50 \%, 90 \%$ and $95 \%$ mortality for laboratory colonies of Lu. longipalpis and P. papatasi to ten insecticides were previously determined using a modified version of the CDC bottle bioassay and the WHO exposure kit [34]. These concentrations can serve as starting points for determining diagnostic doses and diagnostic times from time-response survival curves for a susceptible population of any sand fly species. Recently, Li et al. [31] also describes a bottle bioassay using $20 \mathrm{ml}$ glass scintillation vials to determine lethal times causing $50 \%$ mortality for $P$. papatasi and P. duboscqi exposed to ten pyrethroid and organophosphate insecticides. While not diagnostic doses, these data can be used for comparative purposes for future insecticide resistance studies for $P$. papatasi and $P$. duboscqi, two important Old World Leishmania spp. vectors.

The objective of this study is to define and establish diagnostic doses and diagnostic times using the CDC bottle bioassay for Lu. longipalpis and P. papatasi to ten insecticides. No standardized diagnostic doses exist for insecticides using the CDC bottle bioassay. These diagnostic doses and diagnostic times determined in this study can now be incorporated into future studies assessing insecticide resistance from field-collected sand fly populations.

\section{Methods}

\section{Sand flies}

Laboratory strains of insecticide-susceptible Lu. longipalpis and $P$. papatasi sand flies at Utah State University were derived from 30-year established colonies maintained at the Walter Reed Army Institute of Research 
(WRAIR) (Silver Spring, MD, USA). The original colonies from Walter Reed have never been exposed to insecticides. All life stages were reared and maintained at USU [34-38].

\section{Insecticides}

Ten technical-grade insecticides were used in this study: four pyrethroids [cypermethrin (Sigma-Aldrich, St. Louis, MO, USA), deltamethrin (Sigma-Aldrich, St. Louis, MO, USA), lambda $(\lambda)$-cyhalothrin (Sigma-Aldrich, St. Louis, MO, USA), and permethrin (Chem Service, Inc., West Chester, PA, USA)]; three organophosphates [chlorpyrifos (Sigma-Aldrich, St. Louis, MO, USA), fenitrothion (Sigma-Aldrich, St. Louis, MO, USA), and malathion (Chem Service, Inc., West Chester, PA, USA)]; two carbamates [bendiocarb (Sigma-Aldrich, St. Louis, MO, USA) and propoxur (Sigma-Aldrich, St. Louis, MO, USA)]; and the organochlorine dichlorodiphenyltrichloroethane (DDT) (Sigma-Aldrich, St. Louis, MO, USA). All insecticide dilutions were prepared in acetone, stored in glass bottles, wrapped in aluminum foil, and kept at $4{ }^{\circ} \mathrm{C}$ while not being used [8]. The concentrations of each insecticide used in these experiments are listed in (Table 1). Wholevalue lethal concentrations causing $50 \%$ and $90 \%$ mortality for each insecticide and for each sand fly species from
Denlinger et al. [34] were used as initial concentrations tested for determining diagnostic doses.

\section{Preparation of exposure bottles}

The day before exposing the sand flies, four $1,000-\mathrm{ml}$ glass bottles (Fisher Scientific, Pittsburgh, PA, USA) were prepared by coating them with insecticide, as described in Denlinger et al. [34]. Following Brogdon \& Chan [8] for a $250-\mathrm{ml}$ bottle, $1.0 \mathrm{ml}$ of insecticide at $10.0 \mu \mathrm{g}$ insecticide/ $\mathrm{ml}$ acetone gives a concentration of $10.0 \mu \mathrm{g} / 250-\mathrm{ml}$ bottle. To compensate for these larger bottle sizes and to maintain an equivalence of $\mathrm{X} \mu \mathrm{g}$ insecticide/ $250-\mathrm{ml}$ bottle [8], $4.0 \mathrm{ml}$ of $\mathrm{X} \mu$ g insecticide was used to coat the interior of the 1,000-ml bottle [34] The bottles were coated with insecticide by swirling the acetone: insecticide solution on the bottom, on the sides, and on the lid. The bottle was then placed on a mechanical bottle roller for 30 minutes to dry and reduce the potential for bubble formation. During this time, the lids were slowly loosened to allow the acetone to evaporate. After 30 minutes, the caps were removed, and the bottles were rolled until all of the acetone evaporated. The bottles were then left open to dry overnight in the dark to prevent photodegradation of the insecticides. For each test replicate, one bottle serving as a control was coated with $4.0 \mathrm{ml}$ of acetone [8]. All bottles were re-used

Table 1 Concentrations of ten insecticides used to expose Lu. longipalpis and P. papatasi sand flies

\begin{tabular}{|c|c|c|}
\hline Insecticide (Insecticide class ${ }^{\mathrm{a}}$ ) & Species & Concentration ( $\mu \mathrm{g}$ insecticide/bottle) \\
\hline \multirow[t]{2}{*}{ Cypermethrin (PYR) } & Lu. longipalpis & $5.0,10.0,15.0,20.0$ \\
\hline & P. papatasi & $20.0,25.0,30.0,35.0,40.0,45.0,50.0,55.0,60.0,65.0,70.0,75.0,90.0,95.0$ \\
\hline \multirow[t]{2}{*}{ Deltamethrin (PYR) } & Lu. longipalpis & 5.0, 10.0, 15.0, 20.0, 25.0, 30.0, 35.0, 40.0, 45.0, 50.0, 75.0, 100.0 \\
\hline & P. papatasi & $5.0,10.0,15.0,20.0,25.0,30.0,35.0,40.0,50.0,75.0,100.0$ \\
\hline \multirow[t]{2}{*}{$\lambda$-Cyhalothrin (PYR) } & Lu. longipalpis & $1.0,2.0,3.0,4.0,10.0,20.0,30.0,40.0$ \\
\hline & P. papatasi & $1.0,2.0,3.0,4.0,5.0,6.0,7.0,10.0,20.0,30.0,40.0$ \\
\hline \multirow[t]{2}{*}{ Permethrin (PYR) } & Lu. longipalpis & $5.0,10.0,12.5,15.0,20.0$ \\
\hline & P. papatasi & $10.0,20.0,25.0,30.0,35.0,40.0,45.0,50.0$ \\
\hline \multirow[t]{2}{*}{ Chlorpyrifos (OP) } & Lu. longipalpis & $5.0,10.0,15.0,20.0,25.0,30.0$ \\
\hline & P. papatasi & $20.0,25.0,30.0,35.0,40.0,45.0$ \\
\hline \multirow[t]{2}{*}{ Fenitrothion (OP) } & Lu. longipalpis & $2.0,4.0,6.0,8.0,10.0,12.0,14.0,16.0,18.0,20.0,22.0,24.0,26.0,28.0,30.0,32.0$ \\
\hline & P. papatasi & $5.0,10.0,15.0,20.0,25.0,30.0,35.0,40.0,45.0$ \\
\hline \multirow[t]{2}{*}{ Malathion (OP) } & Lu. longipalpis & $5.0,10.0,15.0,20.0,25.0,30.0,35.0,40.0,45.0$ \\
\hline & P. papatasi & $50.0,75.0,100.0,125.0,130.0,135.0,140.0,145.0$ \\
\hline \multirow[t]{2}{*}{ Bendiocarb (CX) } & Lu. longipalpis & $1.0,2.0,3.0,4.0,5.0,6.0,7.0,8.0$ \\
\hline & P. papatasi & $1.0,2.0,3.0,4.0,5.0,6.0$ \\
\hline \multirow[t]{2}{*}{ Propoxur (CX) } & Lu. longipalpis & $1.0,2.0,3.0,4.0,10.0$ \\
\hline & P. papatasi & $1.0,2.0,3.0,7.0,15.0$ \\
\hline \multirow[t]{2}{*}{ DDT (OC) } & Lu. longipalpis & $\begin{array}{l}\begin{array}{l}2.5,5.0,7.5,10.0,15.0,20.0,50.0,100.0,150.0,200.0,250.0,300.0,350.0,400.0,450.0,500.0,550.0,600.0, \\
630.0,635.0,640.0,645.0,650.0,700.0\end{array}\end{array}$ \\
\hline & P. papatasi & $2.5,5.0,7.5,10.0,50.0,100.0,150.0,200.0,350.0,400.0,450.0,455.0,460.0,465.0,470.0,480.0,490.0,500.0,550.0$ \\
\hline
\end{tabular}


throughout the duration of the experiment. To clean a bottle with residual insecticide, the bottle and lid was first triple-rinsed with acetone; filled with warm, soapy water; drained; rinsed and filled with cold water; drained; and autoclaved for at least 20 minutes. After being autoclaved, the bottles were left to dry for at least one day before being used again [34].

\section{Insecticide exposure tests}

Approximately 12 hours after the bottles were prepared with insecticide, 10-25 adult sand flies at least two days post-eclosion were aspirated from the main colony and gently blown into each bottle [8]. Approximately equal numbers of nulliparous female and male flies were used for each insecticide-coated bottle, while only nulliparous females were used in the control bottle [8]. Sand flies were aspirated into the control bottle first, followed by the four insecticide-coated bottles. Once sand flies had been aspirated into all five bottles, the timer was initiated and recorded as time zero. At time zero, the total number of flies in each bottle was recorded. The number of alive or dead sand flies was recorded at each time point, depending on which was easier to visually determine [8]. All bottles were held horizontally for the duration of the experiment. During initial replicates with the largest doses of DDT, the authors infrequently observed that the legs of some sand flies would become stuck to the interior surface of the bottles during the 60minute exposure. These flies were unable to be removed from the bottles via aspiration. These replicates were not used. To remedy this issue at these high concentrations, the bottles were rotated every few minutes to promote limited hopping and movement of the sand flies. This movement reduced extended surface contact in one place and eliminated the issue of sand flies becoming fixed on the insecticide surface.

The percent mortality at each time point was the average of the percent mortalities of the four replicates. The percent mortality at a time point in the insecticidetreated bottles was corrected with Abbott's formula if mortality in the control bottle ranged between 5 and $20 \%$. Abbott's formula was not used to correct experimental mortalities if the control group mortality was less than $5 \%$. If control group mortalities exceeded $20 \%$, the entire testing replicate was not used [24].

\section{Organophosphates and carbamates}

Mortality was recorded at $0,15,30,35,40,45,60,75$, 90,105 and 120 minutes by gently rotating the bottle (time-to-knockdown) [8]. Sand flies were scored as "dead" if they had difficulty flying, could not fly altogether, or had trouble righting themselves [8]. If all sand flies were scored as dead before 120 minutes, the flies were kept in the bottles and continued to be observed until 120 minutes was reached.

\section{Pyrethroids and DDT}

Mortality was scored during the exposure test (time-toknockdown) to create survival curves as well after 24hours of recovery time (24-h mortality) [8]. During the exposure test, mortality was recorded at $0,15,30,35$, 40,45 and 60 minutes by gently rotating the bottle. Scoring mortality was equivalent to the criteria used for the carbamate and organophosphate insecticides. If all sand flies were scored as dead before 60 minutes, the flies were kept in the bottles until 60 minutes was reached. At the end of the 60 minutes, the sand flies were captured via mechanical aspiration, released into 1pint cardboard containers with a fine mesh screen top, and kept under the same environmental and food source conditions as the main, untreated colonies. Sand flies were held in these containers for 24-hours prior to mortality being recorded. Mortality was corrected with Abbott's formula using the same criteria described above for both the time-to-knockdown and 24-h mortality.

\section{Survival curves}

Time-response survival curves were made for each insecticide for each sand fly species by plotting time on the $\mathrm{X}$-axis against percent mortality on the $\mathrm{Y}$-axis [8]. For each insecticide dose, the percent mortality at each time point is the average mortality between all four insecticide-treated bottles. A diagnostic dose was determined to be the lowest dose tested that caused $100 \%$ mortality between 30 and 60 minutes, the diagnostic time [8].

\section{Results}

A time-response survival curve for each of the ten insecticides for both Lu. longipalpis and P. papatasi was created following Brogdon \& Chan [8]. For all the time-toknockdown survival curves, the time to reach $100 \%$ mortality decreased with increasing insecticide concentrations. Diagnostic doses and diagnostic times for the organophosphates and carbamates are presented in (Table 2). Diagnostic doses and diagnostic times for time-to-knockdown and for 24-h mortality for the pyrethroids and DDT are presented in (Table 3). Representative survival curves for bendiocarb, fenitrothion, permethrin, and DDT are presented in (Figs. 1 and 2). For some insecticides, multiple diagnostic doses and diagnostic times were observed. Whereas for other insecticides, only one diagnostic dose and diagnostic time were observed because all of the other doses that were tested for that specific insecticide either did not cause $100 \%$ mortality between 30 and 60 minutes or they were saturated doses. 
Table 2 Diagnostic doses and diagnostic times for organophosphate and carbamate insecticides at the time-toknockdown

\begin{tabular}{|c|c|c|}
\hline $\begin{array}{l}\text { Insecticide } \\
\text { (Insecticide class }{ }^{\mathrm{a}} \text { ) }\end{array}$ & Species & $\begin{array}{l}\text { Diagnostic dose and diagnostic } \\
\text { time (for time-to-knockdown) }\end{array}$ \\
\hline \multirow[t]{3}{*}{ Chlorpyrifos (OP) } & Lu. longipalpis & $25.0 \mu \mathrm{g} / \mathrm{ml}(30 \mathrm{~min})$ \\
\hline & & 20.0 m/ml (45 min) \\
\hline & P. papatasi & $30.0 \mu \mathrm{g} / \mathrm{ml}(60 \mathrm{~min})$ \\
\hline \multirow[t]{3}{*}{ Fenitrothion (OP) } & Lu. longipalpis & $32.0 \mu \mathrm{g} / \mathrm{ml}$ (45 min) \\
\hline & & $30.0 \mu \mathrm{g} / \mathrm{ml}(60 \mathrm{~min})$ \\
\hline & P. papatasi & $30.0 \mu \mathrm{g} / \mathrm{ml}(60 \mathrm{~min})$ \\
\hline \multirow[t]{2}{*}{ Malathion (OP) } & Lu. longipalpis & $40.0 \mu \mathrm{g} / \mathrm{ml}(60 \mathrm{~min})$ \\
\hline & P. papatasi & 130.0 m/ml (60 min) \\
\hline \multirow[t]{4}{*}{ Bendiocarb (CX) } & Lu. longipalpis & $6.0 \mu \mathrm{g} / \mathrm{ml}(40 \mathrm{~min})$ \\
\hline & & $5.0 \mu \mathrm{g} / \mathrm{ml}(60 \mathrm{~min})$ \\
\hline & P. papatasi & $2.0 \mu \mathrm{g} / \mathrm{ml}$ (30 min) \\
\hline & & $1.0 \mu \mathrm{g} / \mathrm{ml}$ (40 min) \\
\hline \multirow[t]{4}{*}{ Propoxur (CX) } & Lu. longipalpis & 3.0 mg/ml (30 min) \\
\hline & & $2.0 \mu \mathrm{g} / \mathrm{ml}(40 \mathrm{~min})$ \\
\hline & P. papatasi & 3.0 mg/ml (30 min) \\
\hline & & $2.0 \mu \mathrm{g} / \mathrm{ml}(35 \mathrm{~min})$ \\
\hline
\end{tabular}

${ }^{\mathrm{a} O P}$, organophosphate; $C X$, carbamate

\section{Organophosphates}

Two diagnostic doses for $L$. longipalpis have been determined for chlorpyrifos: $20.0 \mu \mathrm{g} / \mathrm{ml}$ at 45 minutes and $25.0 \mu \mathrm{g} / \mathrm{ml}$ at 30 minutes. Only one diagnostic dose was determined for $P$. papatasi to chlorpyrifos: $30.0 \mu \mathrm{g} / \mathrm{ml}$ at 60 minutes. Both Lu. longipalpis and P. papatasi have identical diagnostic doses and diagnostic times for fenitrothion: $30.0 \mu \mathrm{g} / \mathrm{ml}$ at 60 minutes. Lutzomyia longipalpis has an additional diagnostic dose for fenitrothion of $32.0 \mu \mathrm{g} / \mathrm{ml}$ at 45 minutes. For malathion however, the diagnostic doses between species are markedly different. Lutzomyia longipalpis' diagnostic dose is $40.0 \mu \mathrm{g} / \mathrm{ml}$ at 60 minutes, and $P$. papatasi's diagnostic dose is $130.0 \mu \mathrm{g} / \mathrm{ml}$ at 60 minutes.

\section{Carbamates}

Similar to the smaller lethal concentration (LC) values from Denlinger et al. [31], both Lu. longipalpis and $P$. papatasi have very small diagnostic doses. Lutzomyia longipalpis has a diagnostic dose and diagnostic time for bendiocarb of $6.0 \mu \mathrm{g} / \mathrm{ml}$ at 40 minutes or $5.0 \mu \mathrm{g} / \mathrm{ml}$ at 60 minutes. For propoxur, the diagnostic dose and diagnostic time is $3.0 \mu \mathrm{g} / \mathrm{ml}$ at 30 minutes or $2.0 \mu \mathrm{g} / \mathrm{ml}$ at $40 \mathrm{mi}-$ nutes. Phlebotomus papatasi has smaller diagnostic doses and diagnostic times for bendiocarb than Lu. longipalpis:

Table 3 Diagnostic doses and diagnostic times for pyrethroid and DDT insecticides at time-to-knockdown and after 24-hours

\begin{tabular}{|c|c|c|c|}
\hline Insecticide (Insecticide class ${ }^{a}$ ) & Species & $\begin{array}{l}\text { Diagnostic dose and diagnostic time } \\
\text { (for time-to-knockdown) }\end{array}$ & $\begin{array}{l}\text { Diagnostic dose after } 24 \text { hours } \\
\text { for mortality }\end{array}$ \\
\hline \multirow[t]{4}{*}{ Cypermethrin (PYR) } & Lu. longipalpis & $20.0 \mu \mathrm{g} / \mathrm{ml}(40 \mathrm{~min})$ & $20.0 \mu \mathrm{g} / \mathrm{ml}$ \\
\hline & & 10.0 mg/ml (60 min) & \\
\hline & P. papatasi & $95.0 \mu \mathrm{g} / \mathrm{ml}$ (45 min) & $60.0 \mu \mathrm{g} / \mathrm{ml}$ \\
\hline & & 65.0 mg/ml (60 min) & \\
\hline \multirow[t]{7}{*}{ Deltamethrin (PYR) } & Lu. longipalpis & 45.0 g/ml (35 min) & $30.0 \mu \mathrm{g} / \mathrm{ml}$ \\
\hline & & 15.0 mg/ml (40 min) & \\
\hline & & $5.0 \mu \mathrm{g} / \mathrm{ml}(60 \mathrm{~min})$ & \\
\hline & P. papatasi & 45.0 g/ml (35 min) & $25.0 \mu \mathrm{g} / \mathrm{ml}$ \\
\hline & & $25.0 \mu \mathrm{g} / \mathrm{ml}(40 \mathrm{~min})$ & \\
\hline & & 15.0 g/ml (45 min) & \\
\hline & & $5.0 \mu \mathrm{g} / \mathrm{ml}(60 \mathrm{~min})$ & \\
\hline \multirow[t]{5}{*}{$\lambda$-Cyhalothrin (PYR) } & Lu. longipalpis & $4.0 \mu \mathrm{g} / \mathrm{ml}(40 \mathrm{~min})$ & $1.0 \mu \mathrm{g} / \mathrm{ml}$ \\
\hline & & $3.0 \mu \mathrm{g} / \mathrm{ml}$ (45 mins.) & \\
\hline & & $1.0 \mu \mathrm{g} / \mathrm{ml}(60 \mathrm{~min})$ & \\
\hline & P. papatasi & $4.0 \mu \mathrm{g} / \mathrm{ml}(40 \mathrm{~min})$ & $6.0 \mu \mathrm{g} / \mathrm{ml}$ \\
\hline & & $2.0 \mu \mathrm{g} / \mathrm{ml}(60 \mathrm{~min})$ & \\
\hline \multirow[t]{3}{*}{ Permethrin (PYR) } & Lu. longipalpis & 15.0 mg/ml (30 min) & $15.0 \mu \mathrm{g} / \mathrm{ml}$ \\
\hline & P. papatasi & 60.0 mg/ml (40 min) & $55.0 \mu \mathrm{g} / \mathrm{ml}$ \\
\hline & & $50.0 \mu \mathrm{g} / \mathrm{ml}(60 \mathrm{~min})$ & \\
\hline \multirow[t]{2}{*}{ DDT (OC) } & Lu. longipalpis & $7.5 \mu \mathrm{g} / \mathrm{ml}(30 \mathrm{~min})$ & $650.0 \mu \mathrm{g} / \mathrm{ml}$ \\
\hline & P. papatasi & $7.5 \mu \mathrm{g} / \mathrm{ml}$ (30 min) & $470.0 \mu \mathrm{g} / \mathrm{ml}$ \\
\hline
\end{tabular}




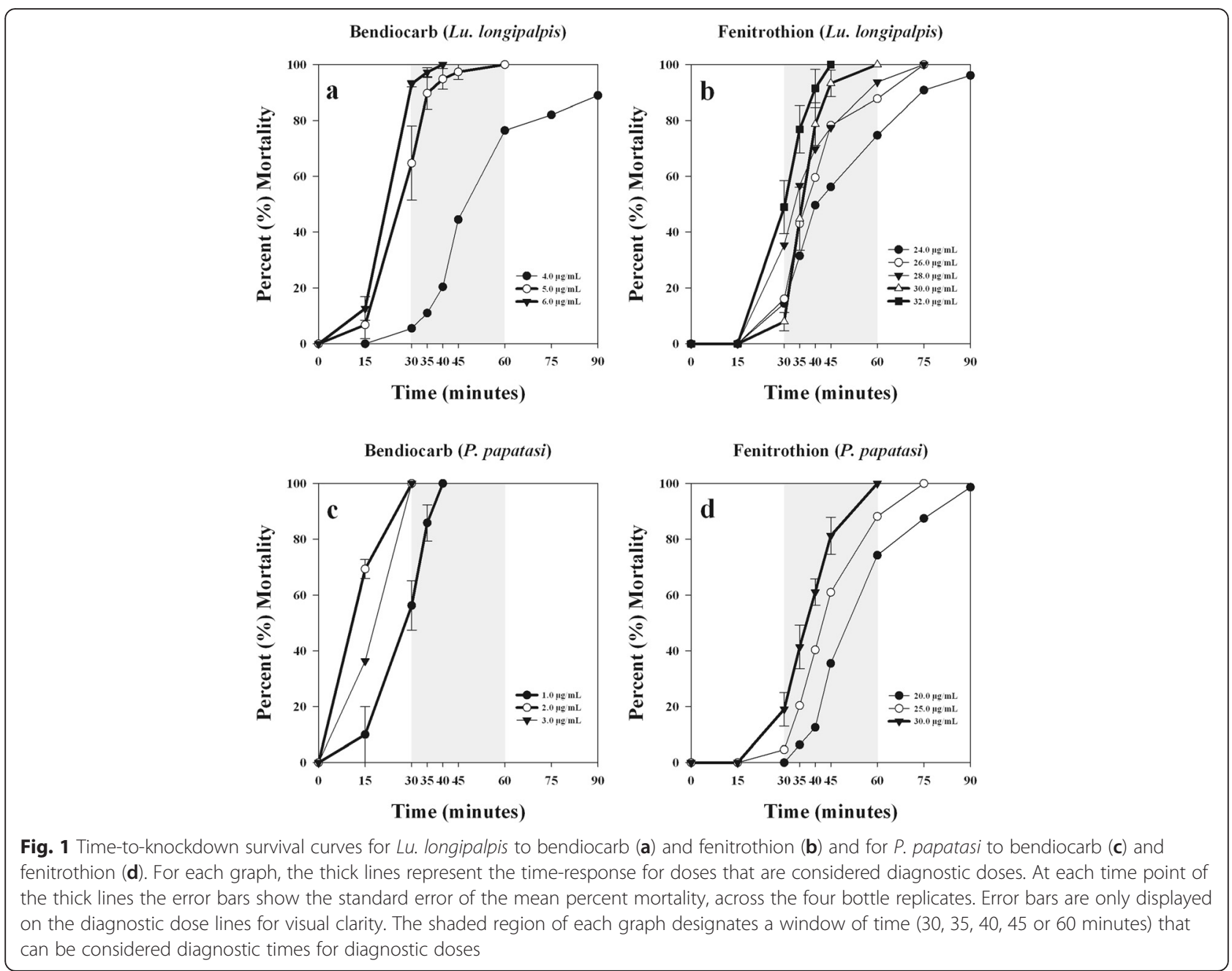

$2.0 \mu \mathrm{g} / \mathrm{ml}$ at 30 minutes or $1.0 \mu \mathrm{g} / \mathrm{ml}$ at 40 minutes. For propoxur, the diagnostic dose is $3.0 \mu \mathrm{g} / \mathrm{ml}$ at 30 minutes or $2.0 \mu \mathrm{g} / \mathrm{ml}$ at 35 minutes, which is almost identical to the diagnostic dose and diagnostic time for $\mathrm{Lu}$. longipalpis.

\section{Pyrethroids}

Phlebotomus papatasi has a larger time-to-knockdown and 24-h mortality for cypermethrin than Lu. longipalpis. Phlebotomus papatasi has two time-to-knockdown diagnostic doses of $65.0 \mu \mathrm{g} / \mathrm{ml}$ at 60 minutes and $95 \mu \mathrm{g} / \mathrm{ml}$ at 45 minutes, and its $24-\mathrm{h}$ mortality diagnostic dose is $60.0 \mu \mathrm{g} / \mathrm{ml}$. Comparatively, Lu. longipalpis' time-toknockdown diagnostic doses are $10.0 \mu \mathrm{g} / \mathrm{ml}$ at 60 minutes and $20.0 \mu \mathrm{g} / \mathrm{ml}$ at 40 minutes, and its 24-h mortality diagnostic dose is $20.0 \mu \mathrm{g} / \mathrm{ml}$. Lutzomyia longipalpis and $P$. papatasi have the same time-to-knockdown diagnostic doses of $5.0 \mu \mathrm{g} / \mathrm{ml}$ at 60 minutes and $45.0 \mu \mathrm{g} / \mathrm{ml}$ at $35 \mathrm{mi}-$ nutes. Lutzomyia longipalpis has an additional diagnostic dose of $15.0 \mu \mathrm{g} / \mathrm{ml}$ at 40 minutes, and P. papatasi has two additional diagnostic doses of $15.0 \mu \mathrm{g} / \mathrm{ml}$ at 45 minutes and $25.0 \mu \mathrm{g} / \mathrm{ml}$ at 40 minutes. Both species have almost equivalent 24-h mortality diagnostic doses to deltamethrin. Lutzomyia longipalpis requires $30.0 \mu \mathrm{g} / \mathrm{ml}$ and $P$. papatasi requires $25.0 \mu \mathrm{g} / \mathrm{ml}$. Besides the carbamates, the time-to-knockdown diagnostic doses for lambda $(\lambda)$-cyhalothrin are the lowest for all ten insecticides. Both $L u$. longipalpis and $P$. papatasi have a diagnostic dose of $4.0 \mu \mathrm{g} / \mathrm{ml}$ at 40 minutes. Lutzomyia longipalpis has two additional diagnostic doses of $1.0 \mu \mathrm{g} / \mathrm{ml}$ at 60 minutes and $3.0 \mu \mathrm{g} / \mathrm{ml}$ at 45 minutes. Phlebotomus papatasi has one additional diagnostic dose of $2.0 \mu \mathrm{g} / \mathrm{ml}$ at 60 minutes. Noticeably, $P$. papatasi has a lambda $(\lambda)$-cyhalothrin $24-\mathrm{h}$ mortality diagnostic dose of $6.0 \mu \mathrm{g} / \mathrm{ml}$, while it only required $1.0 \mu \mathrm{g} / \mathrm{ml}$ to cause $100 \%$ mortality after 24 hours for $L$ u. longipalpis. For permethrin, P. papatasi's time-toknockdown diagnostic doses are $50.0 \mu \mathrm{g} / \mathrm{ml}$ at 60 minutes and $60.0 \mu \mathrm{g} / \mathrm{ml}$ at 40 minutes, and Lu. longipalpis has a diagnostic dose of $15.0 \mu \mathrm{g} / \mathrm{ml}$ in 30 minutes. There is a large difference between the two sand fly species permethrin 24-h mortality diagnostic doses: $55.0 \mu \mathrm{g} / \mathrm{ml}$ and $15.0 \mu \mathrm{g} / \mathrm{ml}$ for P. papatasi and $L u$. longipalpis, respectively. 


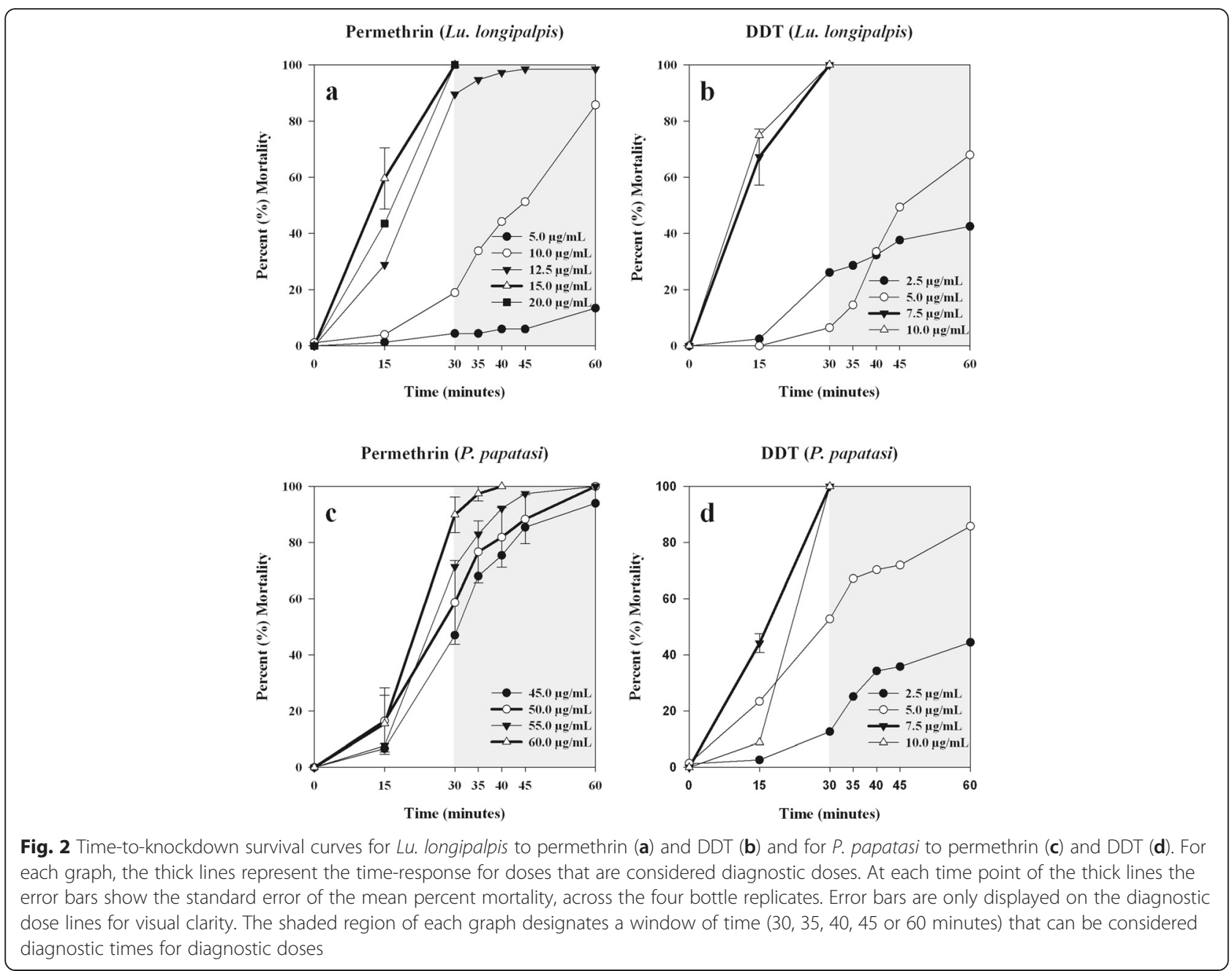

\section{Organochlorine}

Both Lu. longipalpis and P. papatasi have small time-toknockdown diagnostic doses of $7.5 \mu \mathrm{g} / \mathrm{ml}$ at 30 minutes when exposed to DDT. However, both species required very large 24-h mortality diagnostic doses: $650.0 \mu \mathrm{g} / \mathrm{ml}$ of DDT was needed for $\mathrm{Lu}$. longipalpis and $470.0 \mu \mathrm{g} / \mathrm{ml}$ of DDT for P. papatasi.

\section{Discussion}

The objective of this study was to demonstrate that the CDC bottle bioassay can be used to determine diagnostic doses and diagnostic times for phlebotomine sand flies to pyrethroid, organophosphate, carbamate and organochlorine insecticides. This work strengthens the collection of diagnostic doses and diagnostic times that are available for sand flies using the CDC bottle bioassay by presenting for the first time concentrations and times for Phlebotomus spp. [20,32, 33]. The present study provides precise time-to-knockdown diagnostic doses for all ten insecticides for both sand fly species. In addition, for the first time, diagnostic doses for the 24-h recovery period are presented for sand flies to four pyrethroids and DDT.

There have been few studies that have determined diagnostic doses and diagnostic times for Lu. longipalpis using the CDC bottle bioassay. With the results presented in this study, comparisons can now be made for the insecticides malathion, deltamethrin and $\operatorname{lambda}(\lambda)$ cyhalothrin. For our Lu. longipalpis colony, a dose of malathion of $40.0 \mu \mathrm{g} / \mathrm{ml}$ caused $100 \%$ mortality in 60 minutes, while Marceló et al. [33] determined a concentration of $75.0 \mu \mathrm{g} / \mathrm{ml}$ caused $100 \%$ mortality in 25 minutes. Against our colony of $\mathrm{Lu}$. longipalpis, $45.0 \mu \mathrm{g} / \mathrm{ml}$ deltamethrin was needed to cause $100 \%$ mortality in 35 minutes compared to $10.0 \mu \mathrm{g} / \mathrm{ml}$ in 35 minutes [33]. All currently published studies for lambda $(\lambda)$-cyhalothrin have found $L u$. longipalpis to have low diagnostic doses. In the present study, a dose of $4.0 \mu \mathrm{g} / \mathrm{ml}$ was sufficient to cause $100 \%$ mortality in 40 minutes. A dose of $15.0 \mu \mathrm{g} / \mathrm{ml}$ caused $100 \%$ mortality in 30 minutes [33], and Santamaría et al. [32] found $10.0 \mu \mathrm{g} / \mathrm{ml}$ to cause $100 \%$ mortality in approximately 
60 minutes, although only three doses were tested and no precise diagnostic time was provided.

The only direct comparison that can be made for $L u$. longipalpis is for deltamethrin as both colonies (present study and [33]) had equal diagnostic times of 35 minutes. Our colony needed $45.0 \mu \mathrm{g} / \mathrm{ml}$ to cause $100 \%$ mortality, while $\mathrm{Lu}$. longipalpis from [33] only needed $10.0 \mu \mathrm{g} / \mathrm{ml}$. The CDC bottle bioassay protocol designates that a diagnostic dose needs to cause $100 \%$ mortality in the $30 \mathrm{mi}$ nute -60 minute window of exposure (specifically at 30 , $35,40,45$ and 60 minutes) [8]. Some of the diagnostic times determined from Henriquez et al. [20] and Marceló et al. [33] for Lu. evansi and Lu. longipalpis do not fall into this window, and we are therefore not able to make direct comparisons. Future studies using the CDC bottle bioassay need to have comparable diagnostic times to be able to compare diagnostic doses between different populations of a sand fly species.

In accordance with Brogdon \& Chan [8], as small as $5 \mu \mathrm{g} / \mathrm{ml}$ dose increments were used initially when determining diagnostic doses. It was necessary for lambda $(\lambda)$ cyhalothrin, fenitrothion, bendiocarb, propoxur and DDT, to work in increments as small as $1.0 \mu \mathrm{g} / \mathrm{ml}$, $2.0 \mu \mathrm{g} / \mathrm{ml}$, or $2.5 \mu \mathrm{g} / \mathrm{ml}$ because increments of $5.0 \mu \mathrm{g} / \mathrm{ml}$ were too large to effectively determine appropriate diagnostic doses. The small dose increments ensure that diagnostic doses are precise. An innacurate diagnostic dose that is too low in concentration has the potential of displaying false-positives of resistance because individuals will survive during the bioassay. An innacurate diagnostic dose that is too high will potentially display false-negatives of resistance because resistant individuals will be killed even if they are demonstrating a quantifiable level of resistance [8].

One potential limitation of this study was the use of 1,000-ml bottles and not the standard 250-ml bottles [7, 8]. There are though, published examples of non-standard volume bottles that have been used to assess insecticide susceptibility and determination of diagnostic doses and diagnostic times with the CDC bottle bioassay [12, 31]. The $1,000-\mathrm{ml}$ bottles described in this study are the same bottles used in Denlinger et al. [34]. With this increase in volume though, we were unable to use a larger quantity of flies in each bottle ( $>10-25$ of the required number of flies per $250-\mathrm{ml}$ bottle [8]) due to the substantial sand fly demand needed from the lab colonies throughout the entirety of the experiment. The use of the same number of required flies $(10-25)$ in the larger sized bottles potentially may have influenced the diagnostic doses that we observed. Despite an equivalent concentration of insecticide, a smaller density of sand flies exposed per bottle volume (10-25 flies/1,000-ml bottle compared to $10-25$ flies/ $250-\mathrm{ml}$ bottle) and/or potential differences in air volume to bottle surface area may be a factor in the determination of the calculated diagnostic doses and diagnostic times. However, the ten insecticides used are contact insecticides, and the sand flies were regularly observed to be in contact with the interior surface of bottle due to them being poor fliers. The authors suggest that the diagnostic concentrations and times would be very similar for sand flies, regardless of these limited volume differences.

Diagnostic doses and diagnostic times of insecticides for susceptible populations of vector species are fundamentally required when assessing resistance in field populations [39-43]. Accordingly, the diagnostic doses and diagnostic times presented in this study should be used as an initial reference point for determining diagnostic doses and diagnostic times for other insecticide-susceptible populations. The criteria also differ between the WHO exposure kit bioassay and the CDC bottle bioassay. The most recent criterion for resistance for mosquito vectors by the WHO [11] states that resistance is present if there is less than $90 \%$ mortality, while the criterion for resistance by the $\mathrm{CDC}$ states that resistance is present if there is less than $100 \%$ mortality [8]. Using the CDC bottle bioassay to test mosquito populations for resistance, there are examples of employing both the WHO's criterion for resistance $[40,44-47]$ and the CDC's criterion for resistance $[48,49]$. Recommendations from Saeidi et al. [24] suggest tailoring the WHO's resistance criterion for sand flies because of the physiological, behavioral and size differences between mosquitoes and sand flies. We suggest that if the CDC bottle bioassay is used to assess sand fly insecticide susceptibility status, established diagnostic dose and times specific to sand flies and the CDC's criterion for resistance should be used.

One important aspect of the CDC bottle bioassay is the 24-h holding period used for pyrethroids and DDT to allow insects to recover from "knockdown" $[39,41,44,50-52]$. An imperative question with the CDC bottle bioassay is to determine which mortality endpoint to use when assessing resistance: at the time-to-knockdown or at the of the 24-h mortality $[53,54]$. Both the knockdown endpoint and the 24-h mortality endpoint communicate different resistance mechanisms: knockdown resistance $(k d r)$ via targetsite insensitivity or metabolic detoxification. $K d r$ will cause knockdown to be lower than mortality, but metabolic detoxification resistance can cause mortality to be lower than knockdown [53]. Without the 24-h recovery period, the CDC bioassay could miss evidence of metabolic resistance because the lack of a 24-h recovery period does not allow resistant insects to recover; they may be scored as dead during the time-to-knockdown but would have recovered if allowed the 24-h recovery period [53]. In our experiments, the importance of the 24-hour recovery period as part of the CDC bottle bioassay protocol is evident for DDT. 
The time-to-mortality diagnostic doses were 63-87fold greater than the time-to-knockdown diagnostic doses for P. papatasi and Lu. longipalpis, respectively (Table 3). This demonstrates that while sand flies may have small time-to-knockdown diagnostic doses, large concentrations are need to cause $100 \%$ mortality after 24 hours.

The CDC bottle bioassay and WHO exposure kit bioassay are mutually used to detect insecticide resistance. However, a literature search of other studies conducted by [53] found differences in agreement between the two assays in detecting resistance in mosquitoes at both the time-to-knockdown and after 24 hours both at the $90 \%$ and $98 \%$ mortality cutoffs. Several studies have utilized the WHO exposure kit bioassay to assess insecticide resistance in sand flies [19, 21-27]. If future monitoring of insecticide resistance in sand fly populations is to utilize the CDC bottle bioassay, there will need to be a calibration of both the WHO exposure kit bioassay and CDC bottle bioassay. A synchronization of the diagnostic doses and diagnostic times for both assays will need to use the same population of sand flies, such that the same level of mortality can be derived from each assay [53].

The CDC bottle bioassay has been used for many years to track the spread of insecticide resistance in mosquitoes; however, this assay does not assess the intensity of insecticide resistance [54]. The CDC bottle bioassay intensity rapid diagnostic tests (I-RDT's), developed by Bagi et al. [54], follows the CDC bottle bioassay protocol but measures insecticide concentrations $1 \times, 2 \times$, $5 x$ and $10 x$ the known diagnostic doses. The intended goal is not so much with understanding the prevalence of insecticide resistance, but to quantify the intensity of resistance [54]. For sand flies, I-RDT's are not yet necessary because the prevalence of resistance is low and baseline data from field collections are limited. Resistance prevalence for sand flies may be initially low because it has not been assessed very frequently or because it may not be very prevalent $[13,31,55]$. Regardless, knowing the speed with which resistance has developed and spread in mosquito populations demonstrates the need to continue to assess insecticide resistance prevalence in sand fly populations and to prepare I-RDT's in areas where resistance is already present. The diagnostic doses and diagnostic times presented in this study provides necessary baseline data for developing $\mathrm{CDC}$ bottle bioassay I-RDT's for sand flies.

\section{Conclusions}

Evidence of insecticide resistance in worldwide populations of phlebotomine sand flies is a threat to the success of control programs that aim to mitigate the spread of leishmaniasis. It is crucial to have timely insecticide susceptibility data for different sand fly populations. The
CDC bottle bioassay is one method to assess insecticide resistance, but it has been used infrequently with sand flies. With the diagnostic doses and diagnostic times presented here, the CDC bottle bioassay has great potential to be assimilated into sand fly control programs where other resistance-assessing methods are not feasible. The data presented in this study can serve as starting points for determining the susceptibility of field-collected and laboratory-reared $\mathrm{Lu}$. longipalpis and P. papatasi, and for determining diagnostic doses and diagnostic times for other sand fly species of public health concern. Knowing if a population of sand flies is resistant to an insecticide or insecticide class is critical because it allows control strategies to be effectively implemented while not exacerbating the prevalence of insecticide resistance.

\section{Ethical considerations}

The maintenance of SKH1 hairless mice (Charles River, Wilmington, MA, USA) and the experimental animaluse protocol was approved by Utah State University's Institutional Animal-Care and Use Committee.

Competing interests

The authors declare that they have no competing interests.

\section{Authors' contributions}

DSD and SAB conceived and designed the experiment. DSD, JAC, JLA, and CKR contributed to data collection. DSD, JAC, and SAB wrote the manuscript. CKR, DSD, and SAB contributed to the figure designs. All authors read and approved the final manuscript.

\section{Acknowledgments}

We are grateful for Dr. Phillip G. Lawyer and Tobin E. Rowland at WRAIR for providing training on how to maintain sand flies in the laboratory and for providing the necessary sand flies to begin our colonies at USU. We thank Drs. Saul Lozano-Fuentes and Karla Saavedra-Rodriguez in Dr. William C. Black IV's laboratory at Colorado State University (Fort Collins, CO) for training on the CDC bottle bioassay.

\section{Funding}

This work was supported by a Utah State University Research and Projects Grant that enabled data collection.

Received: 30 October 2015 Accepted: 5 April 2016

Published online: 15 April 2016

\section{References}

1. Rivero A, Vézilier J, Weill M, Read AF, Gandon S. Insecticide control of vector-borne diseases: when is insecticide resistance a problem? PLoS Pathog. 2010;6:e1001000.

2. W.H.O. Expert Committee on Insecticides. World Health Organization Technology Report Series $7^{\text {th }}$ Report. Geneva, Switzerland: W.H.O; 1957.

3. Scott JG. Cytochrome P450 and insecticide resistance. Insect Biochem. 1999; 29:757-77.

4. Hemingway J, Field L, Vontas J. An overview of insecticide resistance. Science. 2002;298:96-7.

5. Nauen R. Insecticide resistance in disease vectors of public health importance. Pest Manag Sci. 2007;63:628-33.

6. Surendran S, Karunaratne SHPP, Adams Z, Hemingway J, Hawkes NJ. Molecular and biochemical characterization of a sand fly population from Sri Lanka: evidence for insecticide resistance due to altered esterases and insensitive acetylcholinesterase. Bull Entomol Rev. 2005;95:371-80.

7. Brogdon WG, MCAllister JC. Simplification of adult mosquito bioassays through the use of time-mortality determinations in glass bottles. J Am Mosq Control Assoc. 1998;14:159-64. 
8. Brogdon WG, Chan A. Guideline for evaluating insecticide resistance in vectors using the CDC bottle bioassay / Methods in Anopheles research. Second edition. CDC Atlanta, USA: CDC technical report; 2010. p. 343.

9. Perea EZ, León RB, Salcedo MP, Brogdon WG, Devine GJ. Adaptation and evaluation of the bottle bioassay for monitoring insecticide resistance in disease vector mosquitoes in the Peruvian Amazon. Malar J. 2009:8:208.

10. Aïzoun N, Ossè R, Azondekon R, Alia R, Oussou O, Gnanguenon V, et al. Comparison of the standard WHO susceptibility tests and the CDC bottle bioassay for the determination of insecticide susceptibility in malaria vectors and their correlation with biochemical and molecular biology assays in Benin, West Africa. Parasit Vectors. 2013;6:147.

11. W.H.O. Test procedures for insecticide resistance monitoring in malaria vector mosquitoes. Geneva: W.H.O.; 2013.

12. Elamathi N, Barik TK, Verma V, Velamuri PS, Bhatt RM, Sharma SK, et al. Standardization of a bottle assay- an indigenous method for laboratory and field monitoring of insecticide resistance and comparison with WHO adult susceptibility test. Parasitol Res. 2014;113:3859-66.

13. Alexander B, Maroli M. Control of phlebotomine sandflies. Med Vet Entomol, 2003;17:1-18.

14. Kishore K, Kumar V, Kesari S, Dinesh DS, Kumar AJ, Das P, et al. Vector control in leishmaniasis. Indian J Med Res. 2006:123:467-72.

15. Claborn DM. The biology and control of leishmaniasis vectors. J Glob Infect Dis. 2010;2:127-34.

16. Amóra SSA, Bevilaqua CML, Feijó FMC, Alves ND, Maciel MDV. Control of phlebotomine (Diptera: Psychodidae) leishmaniasis vectors. Neotrop Entomol. 2009;38:303-10.

17. Ready PD. Biology of Phlebotomine Sand Flies as Vectors of Disease Agents. Annu Rev Entomol. 2013;58:227-50.

18. Alvar J, Velez ID, Bern C, Herrero M, Desjeux P, Cano J, et al. Leishmaniasis worldwide and global estimates of its incidence. PLoS One. 2012;7, e35671.

19. Alexander B, Barros VC, de Souza SF, Barros SS, Teodoro LP, Soares ZR, et al. Susceptibility to chemical insecticides of two Brazilian populations of the visceral leishmaniasis vector Lutzomyia longipalpis (Diptera: Psychodidae). Trop Med Int Health. 2009;14:1272-7.

20. Henriquez C, Pereira Y, Cochero S, Bejarano EE. Dosis diagnóstica y umbral de resistencia de Lutzomyia evansi (Diptera: Psychodidae), a dos insecticidas utilizados en salud pública en Colombia: deltametrina y lambdacihalotrina. Rev Entomol Soc Argent Mendoza. 2009;68:287-94.

21. Dinesh DS, Das ML, Picado A, Roy L, Rijal S, Singh SP, et al. Insecticide susceptibility of Phlebotomus argentipes in visceral leishmaniasis endemic districts in India and Nepal. PLoS Negl Trop Dis. 2010;4, e859.

22. Faraj $C$, Ouahabi $S$, Adlaoui EB, el Elkohli M, Lakraa L, el Rhazi $M$, et al. Insecticide susceptibility of Phlebotomus (Paraphlebotomus) sergenti and Phlebotomus (Phlebotomus) papatasi in endemic foci of cutaneous leishmaniasis in Morocco. Parasit Vectors. 2012;5:51.

23. Hassan MM, Widaa SO, Osman OM, Numiary MSM, Ibrahim MA, Abushama HM. Insecticide resistance in the sand fly, Phlebotomus papatasi from Khartoum State, Sudan. Parasit Vectors. 2012;5:46.

24. Saeidi Z, Vatandoost H, Akhavan AA, Yaghoobi-Ershadi MR, Rassi Y, Sheikh $M$, et al. Baseline susceptibility of a wild strain of Phlebotomus papatasi (Diptera: Psychodidae) to DDT and pyrethroids in an endemic focus of zoonotic cutaneous leishmaniasis in Iran. Pest Manag Sci. 2012;68:669-75.

25. Singh R, Kumar P. Susceptibility of the sandfly Phlebotomus argentipes Annandale and Brunetti (Diptera: Psychodidae) to insecticides in endemic areas of visceral leishmaniasis in Bihar, India. Jpn J Infect Dis. 2015;68:33-7

26. Singh RK, Mittal PK, Dhiman RC. Insecticide susceptibility status of Phlebotomus argentipes, a vector of visceral leishmaniasis in different foci in three states of India. J Vector Borne Dis. 2012:49:254-7.

27. Afshar AA, Rassi Y, Sharifi I, Abai MR, Oshaghi MA, Yaghoobi-Ershadi MR, et al. Susceptibility status of Phlebotomus papatasi and P. sergenti (Diptera: Psychodidae) to DDT and deltamethrin in a focus of cutaneous leishmaniasis after earthquake strike in Bam, Iran. Iran J Arthropod-Borne Dis. 2011:5:32-41.

28. Khan SA, Aqueel A, Saleem RQ, Zahoor N, Arooj K, Raza M, et al. Insecticide resistance in sand flies (Phlebotomus papatasi) against bifenthrin and cypermethrin in Chakwal, Pakistan. Eur Acad Res. 2015;3:5349-63.

29. Kumar V, Shankar L, Kesari S, Bhunia GS, Dinesh DS, Mandal R, et al. Insecticide susceptibility of Phlebotmus argentipes \& assessment of vector control in two districts of West Bengal, India. Indian J Med Res. 2015;142: $211-5$.
30. Coleman M, Foster GM, Deb R, Singh RP, Ismail HM, Shivam P, et al. DDTbased indoor residual spraying suboptimal for visceral leishmaniasis elimination in India. Proc Natl Acad Sci U S A. 2015;112:8573-8.

31. Li AY, Pérez de León AA, Linthicum KJ, Britch SC, Bast JD, Debboun M. Baseline susceptibility to pyrethroid and organophosphate insecticides in two Old World sand fly species (Diptera: Psychodidae). US Army Med Dep J. 2015; Jul-Sep:3-9.

32. Santamaría E, Munstermann LE, Ferro C. Aproximación al método CDC para determiner susceptibilidad a insecticidas en vectores de leishmaniasis. Biomedica. 2003;23:115-21.

33. Marceló C, Cabrera OL, Santamaría E. Indicadores de sensibilidad de una cepa experimental de Lutzomyia longipalpis (Diptera: Psychodidae) a tres insecticidas de uso en salud pública en Colombia. Biomedica. 2014;34:624-30.

34. Denlinger DS, Lozano-Fuentes S, Lawyer PG, Black IV WC, Bernhardt SA. Assessing insecticide susceptibility of laboratory Lutzomyia longipalpis and Phlebotomus papatasi sand flies (Diptera: Psychodidae: Phlebotominae). Med Entomol. 2015:52:1003-12

35. Lawyer PG, Rowton ED, Perkins PV, Johnson RN, Young DG. Recent advances in laboratory mass rearing of phlebotomine sand flies. Parassitologia. 1991;33 Suppl 1:361-4.

36. Modi GB, Rowton ED. Laboratory maintenance of phlebotomine sand flies In: Maramorosch M, Mahmood F, editors. Maintenance of human, animal, and plant pathogen vectors. New Delhi: Oxford \& IBH Publishing Co., Pvt. Ltd. p. 109-121.

37. Young DG, Perkins PV, Endris RG. A larval diet for rearing phlebotomine sand flies (Diptera: Psychodidae). J Med Entomol. 1981;18:446.

38. Volf $\mathrm{P}$, Volfova V. Establishment and maintenance of sand fly colonies. J Vector Ecol. 2011;36:S1-9.

39. da-Cunha MP, Lima JB, Brogdon WG, Moya GE, Valle D. Monitoring of resistance to the pyrethroid cypermethrin in Brazilian Aedes aegypti (Diptera: Culicidae) populations collected between 2001 and 2003. Mem Inst Oswaldo Cruz. 2005:100:441-4.

40. Flores AE, Albeldaño-Vázquez W, Salas IF, Badii MH, Becerra HL, Garcia GP, et al. Elevated a-esterase levels associated with permethrin tolerance in Aedes aegypti (L.) from Baja California, Mexico. Pest Biochem Physiol. 2005;82:66-78.

41. Norris LC, Norris DE. Efficacy of long-lasting insecticidal nets in use in Macha, Zambia, against the local Anopheles arabiensis population. Malar J. 2011:10:254.

42. Ocampo CB, Salazar-Terreros MJ, Mina NJ, McAllister J, Brogdon W. Insecticide resistance status of Aedes aegypti in 10 localities in Colombia. Acta Trop. 2011;118:37-44.

43. Ochomo E, Bayoh MN, Brogdon WG, Gimnig JE, Ouma C, Vulule JM, et al. Pyrethroid resistance in Anopheles gambiae s.s. and Anopheles arabiensis in western Kenya: phenotypic, metabolic and target site characterizations of three populations. Med Vet Entomol. 2013;27:156-64.

44. Hargreaves K, Koekemor LL, Brooke BD, Hunt RH, Mthembu J, Coetzee M. Anopheles funestus resistant to pyrethroid insecticides in South Africa. Med Vet Entomol. 2000;14:181-9.

45. Lima JBP, Da-Cunha MP, Da Silva Júnior RC, Galardo AK, Soares SS, Braga IA, et al. Resistance of Aedes aegypti to organophosphates in several municipalities in the State of Rio de Janeiro and Espírito Santo, Brazil. Am J Trop Med Hyg. 2003;68:329-33.

46. Fonseca-González I, Quiñones ML, McAllister J, Brogdon WG. Mixed-function oxidases and esterases associated with cross-resistance between DDT and lambda-cyhalothrin in Anopheles darlingi Root, 1926 populations from Colombia. Mem Inst Oswaldo Cruz. 2009;104:18-26.

47. Fonseca-González I, Quiñones ML, Lenhart A, Brogdon WG. Insecticide resistance status of Aedes aegypti (L.) from Colombia. Pest Manag Sci. 2011; 67:430-7.

48. Fonseca-González I, Cárdenas R, Quiñones ML, McAllister J, Brogdon WG. Pyrethroid and organophosphate resistance in Anopheles (N.) nuneztovari Gabaldón populations from malaria endemic areas in Colombia. Parasitol Res. 2009;105:1399-409.

49. Aïzoun N, Aikkpon R, Akogbétp M. Evidence of increasing L1014F kdr mutation frequency in Anopheles gambiae s.l. pyrethroid resistant following a nationwide distribution of LLINs by the Beninese National Malaria Control Programme. Asian Pac J Trop Biomed. 2014;4:239-43.

50. Saavedra-Rodriguez K, Strode C, Suarez AF, Salas IF, Ranson H, Hemingway J, et al. Quantitative trait loci mapping of genome regions controlling permethrin resistance in the mosquito Aedes aegypti. Genetics. 2008;180: $1137-52$. 
51. Davies TGE, Field LM, Usherwood PNR, Williamson MS. DDT, pyrethrin, pyrethroids, and insect sodium channels. IUBMB Life. 2007;59:151-62.

52. Martins AJ, Lins RMMA, Linss JGB, Peixoto AA, Valle D. Voltage-gated sodium channel polymorphism and metabolic resistance in pyrethroidresistant Aedes aegypti from Brazil. Am J Trop Med Hyg. 2009;81:108-15.

53. Owusu HF, Jančáryová D, Malone D, Müller P. Comparability between insecticide resistance bioassays for mosquito vectors: time to review current methodology? Parasit Vectors. 2015;8:357.

54. Bagi J, Grisales N, Corkill R, Morgan JC, N'Falé S, Brogdon WG, et al. When a discriminating dose assay is not enough: measuring the intensity of insecticide resistance in malaria vectors. Malar J. 2015;14:210.

55. Brogdon WG, MCAllister JC. Insecticide resistance and vector control. Emerg Infect Dis. 1998;4:605-13.

Submit your next manuscript to BioMed Central and we will help you at every step:

- We accept pre-submission inquiries

- Our selector tool helps you to find the most relevant journal

- We provide round the clock customer support

- Convenient online submission

- Thorough peer review

- Inclusion in PubMed and all major indexing services

- Maximum visibility for your research

Submit your manuscript at www.biomedcentral.com/submit
Biomed Central 